winter Olympic Games. It owns all rights to the Olympic symbols, flag, motto, anthem and Olympic Games.

Aims. 'To contribute to building a peaceful and better world by educating youth through sport, practised without discrimination of any kind and in the Olympic Spirit, which requires mutual understanding with a spirit of friendship, solidarity and fair play.'

Finances. The IOC receives no public funding. Its only source of funding is from private sectors, with the substantial part of these revenues coming from television broadcasters and sponsors.

Address: Château de Vidy, Case Postale 356, CH-1007 Lausanne, Switzerland.

Website: http://www.olympic.org

President: Jacques Rogge (Belgium).

\section{International Organization for Migration (IOM)}

Established in Brussels in 1951 to help solve European population and refugee problems through migration, and to stimulate the creation of new economic opportunities in countries lacking certain manpower. IOM is committed to the principle that humane and orderly migration benefits migrants and society.

Members (125 as of Feb. 2009). Afghanistan, Albania, Algeria, Angola, Argentina, Armenia, Australia, Austria, Azerbaijan, Bahamas, Bangladesh, Belarus, Belgium, Belize, Benin, Bolivia, Bosnia and Herzegovina, Brazil, Bulgaria, Burkina Faso, Burundi, Cambodia, Cameroon, Canada, Cape Verde, Chile, Colombia, Congo (Democratic Republic of), Congo (Republic of), Costa Rica, Côte d'Ivoire, Croatia, Cyprus, Czech Republic, Denmark, Dominican Republic, Ecuador, Egypt, El Salvador, Estonia, Finland, France, Gabon, Gambia, Georgia, Germany, Ghana, Greece, Guatemala, Guinea, Guinea-Bissau, Haiti, Honduras, Hungary, India, Iran, Ireland, Israel, Italy, Jamaica, Japan, Jordan, Kazakhstan, Kenya, South Korea, Kyrgyzstan, Latvia, Liberia, Libya, Lithuania, Luxembourg, Madagascar, Mali, Malta, Mauritania, Mauritius, Mexico, Moldova, Mongolia, Montenegro, Morocco, Nepal, Netherlands, New Zealand, Nicaragua, Niger, Nigeria, Norway, Pakistan, Panama, Paraguay, Peru, Philippines, Poland, Portugal, Romania, Rwanda, Senegal, Serbia, Sierra Leone, Slovakia, Slovenia, Somalia, South Africa, Spain, Sri Lanka, Sudan, Sweden, Switzerland, Tajikistan, United Republic of Tanzania, Thailand, Togo, Tunisia, Turkey, Uganda, Ukraine, UK, USA, Uruguay, Venezuela, Vietnam, Yemen, Zambia and Zimbabwe. 18 countries and a large number of government agencies and NGOs have observer status.

Activities. As an intergovernmental body, IOM acts with its partners in the international community to: assist in meeting the operational challenges of migration; advance understanding of migration issues; encourage social and economic development through migration; work towards effective respect of human dignity and the well-being of migrants. Since 1952 the IOM has assisted some $11 \mathrm{~m}$. refugees and migrants to settle in over 125 countries. Throughout 2001 the organization assisted in the humanitarian emergency unfolding in Afghanistan by way of shelter programmes and the registration of IDPs (internally displaced persons), and by meeting the needs of the displaced brought on by drought and conflict. In 2001 IOM launched a 'Migration and Development in Africa Programme' and a 'Migration Policy and Research Programme'. IOM's operational budget for 2009 was US\$631.5m.
Official languages: English, French, Spanish.

Headquarters: Route des Morillons 17, POB 71, 1211 Geneva

19, Switzerland.

Website: http://www.iom.int

Director-General: William Lacy Swing (USA).

\section{International Organization for Standardization (ISO)}

Established in 1947, the International Organization for Standardization is a non-governmental federation of national standards bodies from 157 countries worldwide, one from each country. ISO's work results in international agreements which are published as International Standards. The first ISO standard was published in 1951 with the title 'Standard reference temperature for industrial length measurement'.

Some 15,400 ISO International Standards are available on subjects in such diverse fields as information technology, textiles, packaging, distribution of goods, energy production and utilization, building, banking and financial services. ISO standardization activities include the widely recognized ISO 9000 family of quality management system and standards and the ISO 14000 series of environmental management system standards. Standardization programmes are now being developed in completely new fields, such as food safety, security, social responsibility and the service sector.

Mission. To promote the development of standardization and related activities in the world with a view to facilitating the international exchange of goods and services, and to developing co-operation in the spheres of intellectual, scientific, technological and economic activity.

Headquarters: 1 chemin de la Voie-Creuse, Case postale 56,

CH-1211 Geneva 20, Switzerland.

Website: http://www.iso.org

Secretary-General: Alan Bryden.

\section{International Organization of the Francophonie}

The International Organization of the Francophonie represents 68 countries and provinces/regions (including 13 with observer status) using French as an official language. Objectives include the promotion of peace, democracy, and economic and social development, through political and technical co-operation. The Secretary-General is based in Paris.

Members. Albania, Andorra, Belgium, Benin, Bulgaria, Burkina Faso, Burundi, Cambodia, Cameroon, Canada, Canada-New Brunswick, Canada-Quebec, Cape Verde, Central African Republic, Chad, Comoros, Republic of the Congo, Democratic Republic of the Congo, Côte d'Ivoire, Djibouti, Dominica, Egypt, Equatorial Guinea, France, French Community of Belgium, Gabon, Greece, Guinea, Guinea-Bissau, Haiti, Laos, Lebanon, Luxembourg, Macedonia, Madagascar, Mali, Mauritania, Mauritius, Moldova, Monaco, Morocco, Niger, Romania, Rwanda, St Lucia, São Tomé e Príncipe, Senegal, Seychelles, Switzerland, Togo, Tunisia, Vanuatu, Vietnam. Associate Members. Armenia, 